\title{
Mechanistic Insights into Dissolved Organic Sulfur Photomineralization through the Study of Cysteine Sulfinic Acid
}

\section{Journal Article}

Author(s):

Ossola, Rachele (D); Clerc, Baptiste; McNeill, Kristopher (I)

Publication date:

2020-10-20

Permanent link:

https://doi.org/10.3929/ethz-b-000448959

Rights / license:

In Copyright - Non-Commercial Use Permitted

Originally published in:

Environmental Science \& Technology 54(20), https://doi.org/10.1021/acs.est.0c04340

Funding acknowledgement:

188565 - Reactivity-based characterization of photoexcited natural organic matter (SNF) 


\title{
Mechanistic Insights into Dissolved Organic Sulfur Photomineralization through the Study of Cysteine Sulfinic Acid
}

\author{
Rachele Ossola, Baptiste Clerc, and Kristopher McNeill*
}

Cite This: Environ. Sci. Technol. 2020, 54, 13066-13076

Read Online

ABSTRACT: Photochemical reactions convert dissolved organic matter (DOM) into inorganic and low-molecular-weight organic products, contributing to its cycling across environmental compartments. However, knowledge on the formation mechanisms of these products is still scarce. In this work, we investigate the triplet-sensitized photodegradation of cysteine sulfinic acid, a (photo)degradation product of cysteine, to sulfate $\left(\mathrm{SO}_{4}{ }^{2-}\right)$. We use kinetic analysis, targeted experiments, and previous literature from several fields of chemistry to explain the elementary steps that lead to the release of sulfate. Our analysis indicates that triplet sensitizers act as oneelectron oxidants on the sulfinate $S$ lone pair. The resulting radical undergoes $\mathrm{C}-\mathrm{S}$ fragmentation to form $\mathrm{SO}_{2}$, which becomes hydrated to sulfite/bisulfite (S(IV)). S(IV) is further oxidized to $\mathrm{SO}_{4}{ }^{2-}$ in the presence of triplet sensitizers and oxygen. We point out that the reaction sequence

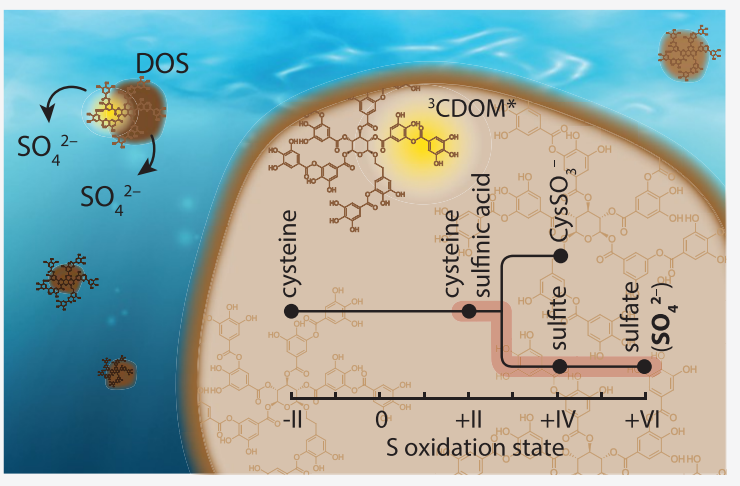
$\mathrm{SO}_{2} \rightleftharpoons \mathrm{S}(\mathrm{IV}) \rightarrow \mathrm{SO}_{4}{ }^{2-}$ is valid independently of the chemical structure of the model compound and might represent a sulfate photoproduction mechanism with general validity for DOS. Our mechanistic investigation revealed that amino acids in general might also be photochemical precursors of $\mathrm{CO}_{2}$, ammonia, acetaldehyde, and $\mathrm{H}_{2} \mathrm{O}_{2}$ and that reaction byproducts can influence the rate and mechanism of S(IV) (photo)oxidation.

\section{INTRODUCTION}

Photodegradation of dissolved organic matter (DOM) plays an essential role in the cycle of main elements, particularly in environments where biological processes are slow such as shallow water bodies at high latitudes. ${ }^{1,2}$ Photodegradation results in the formation of partially oxidized organic matter and low-molecular-weight compounds, including $\mathrm{CO}_{2}, \mathrm{CO}$, lowmolecular-weight organic carbonyls and acids, $\mathrm{PO}_{4}{ }^{3-}, \mathrm{NH}_{4}{ }^{+}$, carbonyl sulfide (OCS), and $\mathrm{SO}_{4}{ }^{2-3-15}$ Many direct and indirect measurements have corroborated the occurrence of sunlight-induced cycling. However, due to the inherently complex nature of DOM, only a handful of studies have investigated the chemical mechanisms underpinning these processes (see Mopper et al. ${ }^{4}$ and references therein).

In this work, we provide a contribution to understanding possible mechanisms responsible for the photochemical formation of sulfate from dissolved organic sulfur (DOS) by investigating the triplet-sensitized photodegradation mechanism of cysteine sulfinic acid $\left(\mathrm{CysSO}_{2}^{-}\right)$. This compound is an oxidation product of cysteine that yields both sulfate and cysteine sulfonic acid $\left(\mathrm{CysSO}_{3}{ }^{-}\right)$under photosensitized conditions (Figure 1). ${ }^{16,17}$ To tackle this research question, we combined kinetic analyses, identification of intermediates, and previous knowledge from the biochemistry literature, an approach that is notably different from previous mechanistic studies of DOM photoproducts.

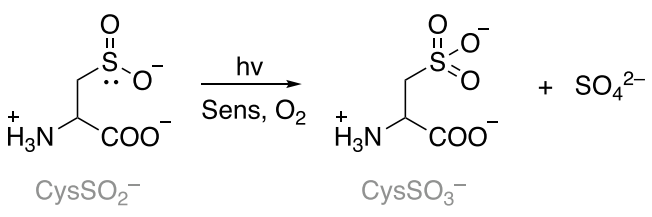

Figure 1. Schematic overview of the reaction mechanism investigated in this work.

Typical strategies to investigate formation mechanisms of DOM photoproducts involve the use of DOM solutions (the source of reactive species) amended with representative model compounds (the substrates). Mechanistic insights are also obtained by evaluating changes in the formation (rate or yields) of DOM photoproducts upon the addition of quenchers or enhancers of specific reactive intermediates. We argue that such approaches (and related ones; Supporting Information, section S1.1) are an excellent starting point to evaluate qualitatively which reactive species might be involved in the formation of certain photoproducts, but they do limit

Received: July 2, 2020

Revised: September 14, 2020

Accepted: September 16, 2020

Published: September 16, 2020

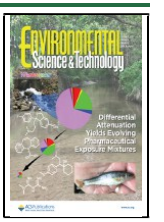


how fully reaction mechanisms can be tested. A general limitation is that usually only final products are detected, an approach that is also prone to false negatives (see section S1.2 and Figure S1). Indeed, to the authors' knowledge, there have only been limited attempts to identify relevant intermediates (i.e., CO in OCS production) $)^{12,18}$ or to link the formation kinetics of the product with the substrate degradation kinetics, ${ }^{15}$ two steps that are needed to corroborate reaction mechanisms. In this work, we demonstrate that detailed and comprehensive mechanistic investigations combined with available knowledge from other fields of chemistry could provide unprecedented insights into DOM photodegradation mechanisms.

To this aim, we first investigate the DOM-sensitized photodegradation kinetics of cysteine and $\mathrm{CysSO}_{2}{ }^{-}$to confirm the intermediate role of the sulfinic acid under environmentally relevant conditions and to motivate its use as a DOS model compound. We then analyze $\mathrm{CysSO}_{2}^{-}$photodegradation kinetics in the presence of model sensitizers to elucidate the role of singlet oxygen $\left({ }^{1} \mathrm{O}_{2}\right)$, triplet excited states, antioxidants, and ground state oxygen on sulfate production from $\mathrm{CysSO}_{2}{ }^{-}$ and to identify relevant metastable intermediates. These experiments unequivocally show that sulfate production from $\mathrm{CysSO}_{2}{ }^{-}$involves the formation of sulfite/bisulfite (S(IV)), which is further oxidized to $\mathrm{SO}_{4}{ }^{2-}$ in the presence of triplet excited states and oxygen. Being independent of the chemical structure of the substrate, the $\mathrm{S}(\mathrm{IV}) \rightarrow \mathrm{SO}_{4}{ }^{2-}$ oxidation pathway might represent a sulfate formation route valid for DOS in general, and not only for $\mathrm{CysSO}_{2}{ }^{-}$. Furthermore, the elucidation of the entire degradation route provided unexpected insights into the possible formation pathways of other compounds that have been reported as DOM photoproducts, including acetaldehyde, $\mathrm{CO}_{2}$, ammonia, and hydrogen peroxide.

\section{MATERIALS AND METHODS}

Chemicals. Furfuryl alcohol (FFA; for synthesis, $\geq 98 \%$ ) and potassium sulfate $(\geq 99 \%)$ were obtained from Merck; FFA was distilled prior to use. L-Cysteic acid monohydrate $\left(\mathrm{CysSO}_{3}{ }^{-}\right.$; $\left.\geq 99 \%\right)$ was obtained from Fluka, while L-cysteine (99\%) was obtained from Acros. Acetonitrile (ACN; HPLC grade), potassium phosphate monobasic ( $\geq 98 \%)$, acetaldehyde (AAld; $\geq 99.9 \%$ ), formaldehyde (FAld; solution in $\mathrm{H}_{2} \mathrm{O}$ $37 \% \mathrm{wt})$, sodium phosphate dibasic dihydrate $(\geq 99.5 \%)$, Lcysteinesulfinic acid monohydrate $\left(\mathrm{CysSO}_{2}{ }^{-} ; 99 \%\right)$, sodium sulfite $(\geq 98 \%)$, phenol ( $\mathrm{PhOH}$; redistilled, $>99+\%)$, lumichrome (LC), perinaphthenone (PN; 97\%), 3'-methoxyacetophenone (3MAP; $\geq 97 \%$ ), zinc 5,10,15,20-tetra(4-pyridyl)$21 H, 23 H$-porphine-tetrakys (methochloride) (Zn(TMPyP); 85\%), and 2,4,6-trimethylphenol (TMP; 99\%) were purchased from Sigma-Aldrich and were used as received. Suwannee River fulvic acid (SRFA, 2S101F) and Mississippi River NOM (MRNOM, 1R110N) were obtained from the International Humic Substances Society (IHSS, St. Paul, Minnesota). Deuterium oxide $\left(\mathrm{D}_{2} \mathrm{O}, 99.8\right.$ atom \%D) was purchased from Armar Isotopes. All aqueous solutions were prepared with nanopure water $(>18 \mathrm{M} \Omega \mathrm{cm}$, Barnstead Nanopure Diamond system or Merck Milli-Q IQ 7000 system). Cysteine and sodium sulfite stock solutions were prepared daily.

Photolysis Experiments. Photolysis experiments were performed using a Rayonet photoreactor equipped with a fan and a motorizable turntable (Southern New England Ultraviolet Co.). In general, experimental solutions contained 50 $\mu \mathrm{mol} \mathrm{L} \mathrm{L}^{-1}$ of the substrate (cysteine, $\mathrm{CysSO}_{2}{ }^{-}$, or $\mathrm{Na}_{2} \mathrm{SO}_{3}$ ), a sensitizer (MRNOM, 3MAP, Zn(TMPyP), PN, or LC), and an eventual amendment $\left(\mathrm{D}_{2} \mathrm{O}\right.$, SRFA, MRNOM, phenol, acetaldehyde, or formaldehyde) and were prepared in

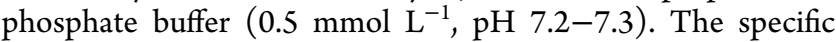
composition of each experimental solution is provided in section $\mathrm{S} 2$ and in Table S1. At this $\mathrm{pH}, \mathrm{CysSO}_{2}{ }^{-}$and $\mathrm{CysSO}_{3}{ }^{-}$ are present mostly as bideprotonated species (99\% and 96\%, respectively), cysteine is present mostly as monodeprotonated species $(87 \%)$, while $\mathrm{Na}_{2} \mathrm{SO}_{3}$ is present both in the bisulfite $\left(\mathrm{HSO}_{3}{ }^{-}, 44 \%\right)$ and sulfite $\left(\mathrm{SO}_{3}{ }^{2-}, 56 \%\right)$ form and is thus indicated generically as S(IV) (section S3 and Figure S3). Experimental solutions $(10 \mathrm{~mL})$ were placed in open borosilicate test tubes (Pyrex, $15 \times 85 \mathrm{~mm}$, Corning Inc.) and were irradiated with UV lamps alongside an FFA solution (40 $\mu \mathrm{mol} \mathrm{L}^{-1}$ in phosphate buffer, $\mathrm{pH} 7.2-7.3$ ) amended with the same photosensitizer, which was used to indirectly quantify light intensity during irradiation. Details concerning irradiation sources are in Table S1 and Figure S2. At each time point, an aliquot was withdrawn for ion chromatography (IC, $1 \mathrm{~mL}$ ) or ultrahigh-performance liquid chromatography (UPLC, 150 $\mu \mathrm{L})$ analyses. Experiments were performed at least in duplicates. When relevant, we quantified the absolute irradiance via $p$-nitroanisole/pyridine actinometry. ${ }^{19} \mathrm{We}$ also performed control experiments that confirmed that $\mathrm{CysSO}_{3}{ }^{-}$ and sulfate are photochemically stable end products and that direct photolysis is minimal under UVB irradiation (Figure S5).

To investigate the role of $\mathrm{O}_{2}$, we used a modified experimental setup. We first prepared $100 \mathrm{~mL}$ of a solution containing $\mathrm{CysSO}_{2}^{-}\left(50 \mu \mathrm{mol} \mathrm{L}{ }^{-1}\right)$ and $3 \mathrm{MAP}\left(30 \mu \mathrm{mol} \mathrm{L}^{-1}\right)$ in phosphate buffer, and we aliquoted this solution into borosilicate test tubes ( $3.5 \mathrm{~mL}$ each, one per time point). The test tubes were capped with rubber stoppers, purged with argon (99.999\% purity, Carbagas AG) for $10 \mathrm{~min}$, and irradiated with UVB light. At each time point, two test tubes were withdrawn for sampling and replaced with water-filled test tubes to maintain a constant light field inside the photoreactor. In this experiment, the initial 3MAP concentration was increased from 20 to $30 \mu \mathrm{mol} \mathrm{L}^{-1}$ to try to afford complete $\mathrm{CysSO}_{2}{ }^{-}$degradation. At the end of the anoxic phase, the irradiated solutions leftover after sampling $(\approx 50$ $\mathrm{mL}$ in total) were reoxygenated with compressed air for $2 \mathrm{~min}$, amended with $3 \mathrm{MAP}\left(20 \mu \mathrm{mol} \mathrm{L}{ }^{-1}\right)$ to replenish the sensitizer pool, and irradiated for an additional 45 min with UVB bulbs.

Sample Analysis. Ion Chromatography Analyses (IC). $\mathrm{CysSO}_{2}{ }^{-}, \mathrm{CysSO}_{3}{ }^{-}$, sulfite, and sulfate were quantified with a DX-320 IC instrument (Thermo Scientific, Sunnyvale, CA, USA) equipped with an EG40 eluent gradient generator, a Dionex Ion Pack AG11-HC RFIC $4 \mathrm{~mm}$ column and its guard column, a Dionex AERS $5004 \mathrm{~mm}$ electric suppressor, and an electrical conductivity detector. The sample injection volume was $200 \mu \mathrm{L}$, the flow rate was $1.5 \mathrm{~mL} \mathrm{~min}^{-1}$, and the $\mathrm{KOH}$ gradient was as follows: $0-5 \mathrm{~min}, 17 \mathrm{mmol} \mathrm{L}^{-1}$; 5-6 $\mathrm{min}, 17$ to $40 \mathrm{mmol} \mathrm{L}^{-1}$; 6-8 $\mathrm{min}, 40 \mathrm{mmol} \mathrm{L}^{-1}$; $8-8.1 \mathrm{~min}, 40$ to 17 mmol L ${ }^{-1}$; 8.1-10 min, $17 \mathrm{mmol} \mathrm{L}^{-1}$. In these conditions, $\mathrm{CysSO}_{2}{ }^{-}, \mathrm{CysSO}_{3}{ }^{-}$, sulfite, and sulfate eluted at 4.1, 5.9, 6.1, and $6.7 \mathrm{~min}$, respectively, while phosphate (present in the buffer) eluted at $8.9 \mathrm{~min}$. All compounds showed linear response between 1 and $60 \mu \mathrm{mol} \mathrm{L}^{-1}$, with no interferences from the relatively high sulfate background of MRNOM $(\approx 15$ $\mu \mathrm{mol} \mathrm{L}{ }^{-1}$ at $20 \mathrm{mg}_{\mathrm{C}} \mathrm{L}^{-1}$; see also Ossola et al. $\left.{ }^{14}\right)$. Phosphate concentration was optimized to allow good buffering capacity 
(variation during and across experiments of $\pm 0.2 \mathrm{pH}$ units) and good IC performance. This gradient did not allow for separation of $\mathrm{CysSO}_{3}{ }^{-}$from sulfite when they were present simultaneously in the reaction mixture. We therefore conducted control experiments to confirm that sulfite was present at low enough concentrations to cause only minor variations in our results also during oxic irradiation experiments (section S5 and Figure S6). In the unamended S(IV) degradation experiment, formaldehyde was added to IC samples $\left(0.5 \mu \mathrm{L}\right.$ of a $0.1 \mathrm{~mol} \mathrm{~L}^{-1}$ formaldehyde solution for $1 \mathrm{~mL}$ of sample) right after collection to prevent dark conversion to sulfate. ${ }^{20,21}$

Other Analyses. FFA and TMP were quantified via ultrahigh-performance or high-performance liquid chromatography (UPLC or HPLC) following published procedures. ${ }^{22}$ Cysteine was also quantified via UPLC following monobromobimane functionalization according to Chu et al. ${ }^{23} \mathrm{UV}$ vis analyses were performed with a Cary 100 Bio spectrophotometer (Varian) in double-beam mode using a 1 $\mathrm{cm}$ path length quartz cuvette and $0.5 \mathrm{mmol} \mathrm{L}^{-1}$ phosphate buffer as the blank. We used UV-vis spectra for screening factor calculation in DOM-amended samples and for characterizing 3MAP depletion kinetics under oxic and anoxic conditions.

Data Analysis and Error Significance. In general, $\mathrm{CysSO}_{2}{ }^{-}$ kinetic data were fitted according to a one-step three-product kinetic model, i.e., $\mathrm{A} \rightarrow \mathrm{P}_{1}+\mathrm{P}_{2}+\mathrm{P}_{3}$ (section S6). Data points from at least duplicate experiments were pooled together and fit to eqs 1-3 using a global fitting routine in Matlab (R2018b, nlinmultifit function ${ }^{24}$ ), which directly provided product yields $\left(\Phi_{\mathrm{CysSO}_{3}}{ }^{-}\right.$and $\left.\Phi_{\text {sulfate }}\right)$ and the pseudo-first-order degradation rate constant $\left(k_{\mathrm{obs}, \mathrm{Cys} \mathrm{SO}_{2}}^{-}\right)$as the outputs.

$$
\begin{aligned}
& \frac{\left[\mathrm{CysSO}_{2}^{-}\right]}{\left[\mathrm{CysSO}_{2}^{-}\right]_{0}}=e^{-k_{\mathrm{obs}, \mathrm{Cys} \mathrm{O}_{2}}{ }^{-t}} \\
& \frac{\left[\mathrm{CysSO}_{3}^{-}\right]}{\left[\mathrm{CysSO}_{2}^{-}\right]_{0}}=\Phi_{\mathrm{CysO}_{3}^{-}}\left(1-e^{-k_{\mathrm{obs}, \mathrm{YySO}}{ }^{-t}}\right) \\
& \frac{\left[\mathrm{SO}_{4}{ }^{2-}\right]-\left[\mathrm{SO}_{4}{ }^{2-}\right]_{\text {background }}}{\left[\mathrm{CysSO}_{2}^{-}\right]_{0}}=\Phi_{\text {sulfate }}\left(1-e^{-k_{\mathrm{obs}, \mathrm{CySO}_{2}}{ }^{-t}}\right)
\end{aligned}
$$

In 3MAP-sensitized experiments, sulfate concentrations were corrected for the small sulfate background present in the reaction matrix, either nanopure water $\left(\leq 0.1 \mu \mathrm{mol} \mathrm{L}{ }^{-1}\right)$ or DOM $\left(0.1-15 \mu \mathrm{mol} \mathrm{L}^{-1}\right)$, while, in DOM-sensitized experiments, they were corrected at each time point for sulfate production from $\mathrm{DOM}^{14}$ (eq 3). Unless otherwise stated, errors and error bars are standard errors obtained from the square root of the diagonal elements of the covariance matrix and therefore represent standard errors of the fitting parameters. Note that, in every experimental condition, $\Phi_{\mathrm{CysSO}_{3}}{ }^{-}+\Phi_{\text {sulfate }}<1$, indicating the formation of one or more minor products in addition to sulfate and $\mathrm{CysSO}_{3}{ }^{-}$. No attempts were made to close the mass balance.

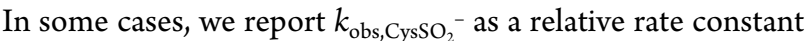
(compared to a standard condition) in order to account for variations in light intensity that we observed due to aging of the light bulbs (i.e., with $6 \times$ UVB lamps, the absolute irradiance integrated between 290 and $400 \mathrm{~nm}$ varied between 40 and $50 \mathrm{~J} \mathrm{~s}^{-1} \mathrm{~m}^{-2}$ ). Light intensity was also indirectly quantified on a daily basis by measuring singlet oxygen steady- state concentrations $\left(\left[{ }^{1} \mathrm{O}_{2}\right]_{\mathrm{ss}}\right)$. These values were obtained from FFA depletion data using $k_{\mathrm{rxn},{ }^{1} \mathrm{O}_{2}}^{\mathrm{FFA}}$ from Appiani et al. ${ }^{25}$ (section S7). We also used $\left[{ }^{1} \mathrm{O}_{2}\right]_{\mathrm{ss}}$ to estimate triplet steadystate concentrations, as $\left[{ }^{3} \text { Sens }{ }^{*}\right]_{s s}=\left[{ }^{1} \mathrm{O}_{2}\right]_{s s} / C^{\prime}$, where $C^{\prime}$ is the experimental ratio $\left[{ }^{1} \mathrm{O}_{2}\right]_{\mathrm{ss}}^{\mathrm{FFA}} /\left[{ }^{3} \text { Sens }{ }^{*}\right]_{\mathrm{ss}}^{\mathrm{TMP}}$ (section 57 ). In agreement with previous measurements, ${ }^{22} C^{\prime}=1.24 \pm 0.04$ for 3MAP, $1.75 \pm 0.07$ for PN, and $2.2 \pm 0.8$ for LC. When using DOM as the antioxidant, we used the solution absorbance before irradiation to calculate the screening factor $\left(\mathrm{SF}_{314}\right)$ at $314 \mathrm{~nm}$ (the wavelength of the action spectrum maximum). The corrected pseudo-first-order rate constant was obtained as $k_{\text {obs,CysSO}}{ }_{2}^{-} / \mathrm{SF}_{314}$.

\section{RESULTS AND DISCUSSION}

Motivations on the Choice of $\mathrm{CysSO}_{2}^{-}$as a DOS Model Compound. A series of reasons motivated our decision to use $\mathrm{CysSO}_{2}^{-}$as a DOS model compound. $\mathrm{CysSO}_{2}{ }^{-}$is a major degradation product of cysteine in reactions photosensitized by chromophoric DOM (i.e., it is a singlet oxygen reaction product $)^{23}$ and also in biological systems. $^{26-29}$ Cysteine has been detected in surface waters as the free amino acid $\left(0.3-29 \mathrm{nmol} \mathrm{L}^{-1}\right),{ }^{30,31}$ as a part of metalbinding polypeptides such as glutathione $(0.03-10 \mathrm{nmol}$ $\left.\mathrm{L}^{-1}\right)^{31-33}$ and phytochelatins $\left(0.01-15 \mathrm{nmol} \mathrm{L}^{-1}\right){ }^{34}$ and is also a component of proteins. ${ }^{27}$ Furthermore, several authors demonstrated that cysteine is a precursor of OCS, ${ }^{11-13,18,35-37}$ $\mathrm{CS}_{2}{ }^{12,36,37}$ and $\mathrm{SO}_{4}{ }^{2-14}$

However, despite being present in the environment and being a precursor of sulfate and other DOS photoproducts, we argue that cysteine is not the most appropriate substrate for the scope of our work. Based on the extensive literature on cysteine oxidation, ${ }^{23,27,28,38}$ we reasoned the conversion of cysteine (i.e., $S(-\mathrm{II})$, the most reduced form of $S$ ) to sulfate (i.e., $S(+V I)$, the most oxidized form of $S$ ) would certainly be a multistep reaction, with most steps not directly relevant for understanding sulfate production

Preliminary DOM-sensitized experiments confirmed that cysteine is not a direct precursor of sulfate. As one can see in Figure 2A, in the presence of Mississippi River NOM, cysteine was degraded quickly during the first hour of irradiation, while sulfate only appeared after an induction period. This kinetic behavior is typical of a multistep reaction (section S6) and suggests that there is at least one metastable intermediate between cysteine and $\mathrm{SO}_{4}{ }^{2-}$. Indeed, during this reaction, we also detected small amounts of $\mathrm{CysSO}_{2}{ }^{-}$, with kinetics typical of a reactive intermediate (i.e., growth-decay kinetics; Figure S7). We also point out that the growth of $\mathrm{CysSO}_{2}{ }^{-}$is considerably slower than the decay of cysteine, suggesting that also the conversion of cysteine to its sulfinic acid is a multistep reaction. This is consistent with previous literature on cysteine oxidation, ${ }^{27,28,38}$ and it is also expected based on differences in oxidation states (i.e., conversion of $S(-\mathrm{II})$ to $\mathrm{S}(+\mathrm{II})$ is a formal loss of $4 \mathrm{e}^{-}$; see Figure 2C). Furthermore, the mass balance indicates that $6.6 \%$ of cysteine was converted into $\mathrm{SO}_{4}{ }^{2-}$ after $5 \mathrm{~h}$ of irradiation, a considerably higher yield compared to what has been reported for OCS under similar conditions (i.e., $0.02 \%$ to $0.12 \%) .{ }^{18,36}$ This result agrees with published photoproduct distributions of freshwater $\operatorname{DOS}^{14}$ and hints that the mechanism of hydrolysis and oxidation of OCS is not a major sulfate formation pathway from the photodegradation of cysteine. 
A

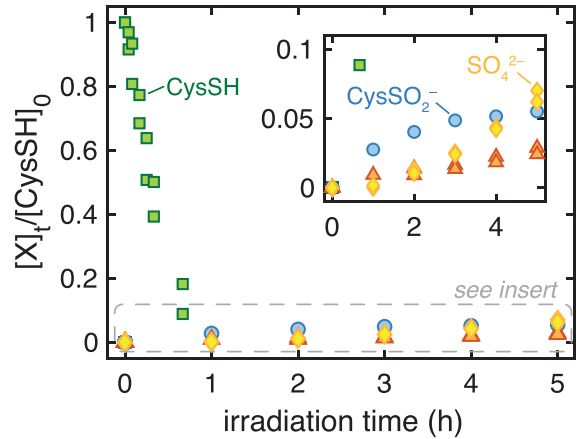

B

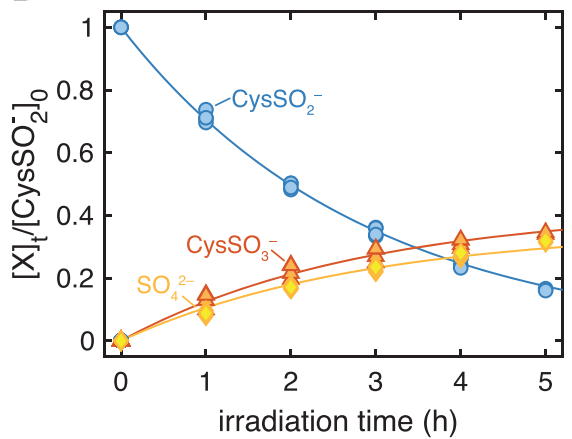

C

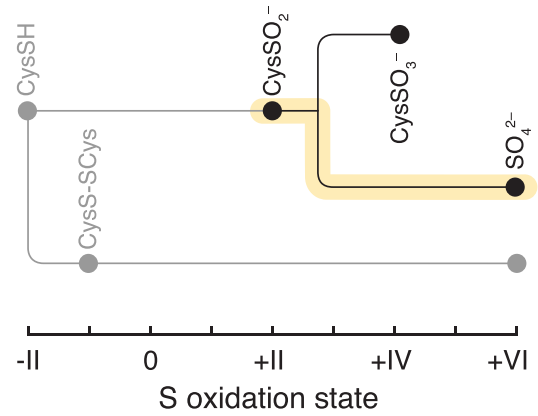

Figure 2. A. Cysteine photodegradation kinetics in the presence of MRNOM (20 $\mathrm{mg}_{\mathrm{C}} \mathrm{L}^{-1}, \mathrm{pH}=7.5$ (unbuffered), $6 \times \mathrm{UVB}$ lamps; green squares). The inset shows the reaction kinetics of $\mathrm{CysSO}_{2}{ }^{-}$(blue circles), $\mathrm{CysSO}_{3}{ }^{-}$(orange triangles), and sulfate (yellow diamonds) during the same experiment. B. Cysteine sulfinic acid photodegradation kinetics in the presence of MRNOM $\left(20 \mathrm{mg}_{\mathrm{C}} \mathrm{L}^{-1}, \mathrm{pH}=7.5\right.$ (unbuffered), $6 \times \mathrm{UVB}$ lamps; blue circles). Lines indicate nonlinear fits performed according to eqs 1-3. C. Overview of cysteine degradation to sulfate deduced from DOMsensitized experiments. Pathways in gray are not directly relevant for understanding sulfate production or have not been investigated in this study. Sulfate production via cystine (CysS-SCys) was identified as an additional pathway in preliminary experiments (section S8 and Figure S8). In this paper, the notation "S(IV)" indicates only sulfite/bisulfite and not generic S compounds with a $+\mathrm{IV}$ oxidation state (i.e., $\mathrm{CysSO}_{3}^{-}$).

A second experiment using $\mathrm{CysSO}_{2}{ }^{-}$as the substrate (Figure 2B) confirmed its nature as intermediate in the formation of sulfate from cysteine. In this case, the reaction showed apparent first-order kinetics, with the $\mathrm{CysSO}_{2}{ }^{-}$degradation rate equivalent to the sulfate formation rate. While apparent first-order kinetics is consistent with a one-step process, it is also consistent with a multistep process with a ratedetermining first step and one or more fast follow-up steps (section S6). We believe the latter situation pertains here, since conversion of sulfinate $(\mathrm{S}(+\mathrm{II}))$ to sulfate $(\mathrm{S}(+\mathrm{VI}))$ requires the loss of $4 \mathrm{e}^{-}$(Figure 2C).

An additional reason for using $\mathrm{CysSO}_{2}{ }^{-}$as the substrate is the body of biochemistry literature involving its oxidation to $\mathrm{CysSO}_{3}{ }^{-}$, the second end product (recently reviewed by Conrado et al. ${ }^{17}$ ), which can be used to inform and complement our mechanistic investigation. Known $\mathrm{CysSO}_{2}{ }^{-}$ oxidants include $\mathrm{OH}^{\bullet}$, carbonate radicals, and $\mathrm{NO},{ }^{\bullet}$ all of which can be formed in vivo from the decomposition of peroxynitrite radicals (dark reactions). ${ }^{39}$ In all cases, $\mathrm{CysSO}_{2}{ }^{-}$ degradation is triggered by one-electron oxidation of the $\mathrm{S}$ lone pair to form a sulfinyl radical $\left(\mathrm{CysSO}_{2}{ }^{\circ}\right)$, which is trapped by $\mathrm{O}_{2}$ and decomposes further to $\mathrm{CysSO}_{3}{ }^{-17}$ In these studies, $\mathrm{SO}_{4}{ }^{2-}$ production is generally not mentioned. An exception is Harman et al., ${ }^{40}$ who reported the formation of a sulfur trioxide radical adduct following the disappearance of the sulfinyl radical adduct signal (via EPR spectroscopy), hinting that $\mathrm{CysSO}_{2}{ }^{\bullet}$ can undergo fragmentation and release $\mathrm{SO}_{2}$. Another piece of evidence for sulfate production comes from Pecci and coauthors, ${ }^{16}$ who investigated the indirect photochemistry of $\mathrm{CysSO}_{2}{ }^{-}$in the context of photodynamic therapy (i.e., the use of photosensitizers and light to treat tumors and other diseases). ${ }^{41}$ Pecci et al. used methylene blue as the model sensitizer and common ${ }^{1} \mathrm{O}_{2}$ enhancers and quenchers to elucidate the mechanism. According to their results, $\mathrm{CysSO}_{2}{ }^{-}$ is degraded via two pathways: one, triggered by ${ }^{1} \mathrm{O}_{2}$ and resulting in the formation of $\mathrm{CysSO}_{3}{ }^{-}$and $\mathrm{H}_{2} \mathrm{O}_{2}$, and the other, initiated by the triplet state of the sensitizer ( ${ }^{3} \mathrm{Sens}{ }^{*}$ ) and resulting in the formation of $\mathrm{SO}_{4}{ }^{2-}, \mathrm{CO}_{2}, \mathrm{NH}_{4}^{+}$, and acetaldehyde in equimolar amounts. Under anoxic conditions, neither $\mathrm{CysSO}_{3}{ }^{-}$nor sulfate was formed.

Photodegradation in the Presence of a Model Sensitizer. In their study, Pecci et al. ${ }^{16}$ concluded that
${ }^{3}$ Sens* $($ Sens $=$ methylene blue $)$ can degrade $\mathrm{CysSO}_{2}{ }^{-}$to form sulfate. In order to corroborate this finding and to establish reference reaction kinetics, we performed a photodegradation experiment using $3^{\prime}$-methoxyacetophenone as the model sensitizer (3MAP, $20 \mu \mathrm{mol} \mathrm{L} \mathrm{L}^{-1}$ in phosphate buffer, $\mathrm{pH}$ 7.2-7.3). 3MAP was preferred over methylene blue because its excited state reduction potential $\left(E^{0 *}\right)$ is similar to the average value for $\mathrm{DOM}^{42}$ and because it absorbs in a spectral range that is more relevant for DOM. Under these conditions, $\mathrm{CysSO}_{2}{ }^{-}$degradation followed pseudo-first-order kinetics (filled blue circles in Figure $3 \mathrm{~A}$ ), with a unimolecular rate constant $\left(k_{\mathrm{obs}, \mathrm{CysSO}_{2}}{ }^{-}\right)$of $(6.22 \pm 0.18) \times 10^{-2} \mathrm{~min}^{-1}$ (irradiance $=48 \mathrm{~J} \mathrm{~s}^{-1} \mathrm{~m}^{-2}$ ). The disappearance of the parent compound was followed by the formation of two products, $\mathrm{CysSO}_{3}{ }^{-}$and sulfate, which qualitatively agrees with Pecci et al. ${ }^{16}$ and with the results obtained using MRNOM as the sensitizer (Figure 2B). Also in this case, we fitted our data to a one-step three-product kinetic model (eqs 1-3), where the products were $\mathrm{SO}_{4}{ }^{2-}, \mathrm{CysSO}_{3}{ }^{-}$, and "other". From these data and the model fit, we obtained product yields of $\Phi_{\mathrm{CysSO}_{3}}{ }^{-}=$ $0.18 \pm 0.01$ and $\Phi_{\text {sulfate }}=0.67 \pm 0.01$. This data is consistent with $\mathrm{CysSO}_{2}{ }^{-}$oxidation being the rate-determining step for the entire reaction sequence also when using model sensitizers. The reaction is considerably faster with $3 \mathrm{MAP}$ as the sensitizer than with MRNOM $\left(k_{\mathrm{obs}, \mathrm{CysSO}_{2}}^{\mathrm{MRNOM}}=(0.58 \pm 0.04) \times 10^{-2}\right.$ $\min ^{-1}$ ) and has different product yields, which reflects differences in steady-state concentrations of photochemically produced intermediates and triplet rate constants (Table S3). ${ }^{43}$ This result hints that other reactive species formed only in the presence of $\mathrm{DOM}$ (e.g., $\mathrm{OH}^{\bullet}$ ) might activate additional degradation pathways.

The Role of Singlet Oxygen. One goal of this work was to reassess the role of ${ }^{1} \mathrm{O}_{2}$, which was proposed to be responsible for the formation of $\mathrm{CysSO}_{3}{ }^{-16}$ We first repeated the diagnostic test that Pecci et al. ${ }^{16}$ employed to characterize the role of ${ }^{1} \mathrm{O}_{2}$, i.e., we performed an irradiation experiment using $80 \% \mathrm{D}_{2} \mathrm{O}$ as the solvent (Figure S9A). Under these conditions, ${ }^{1} \mathrm{O}_{2}$ steady-state concentrations $\left(\left[{ }^{1} \mathrm{O}_{2}\right]_{\mathrm{ss}}\right)$ are expected to be 4.3 times higher; ${ }^{44}$ thus, we anticipated a considerable enhancement in $k_{\mathrm{obs}, \mathrm{CysSO}_{2}}{ }^{-}$. Contrary to this expectation, we observed no rate constant increase in heavy 
A

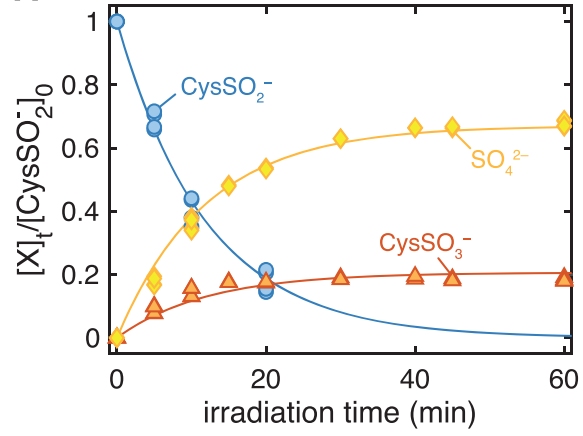

B

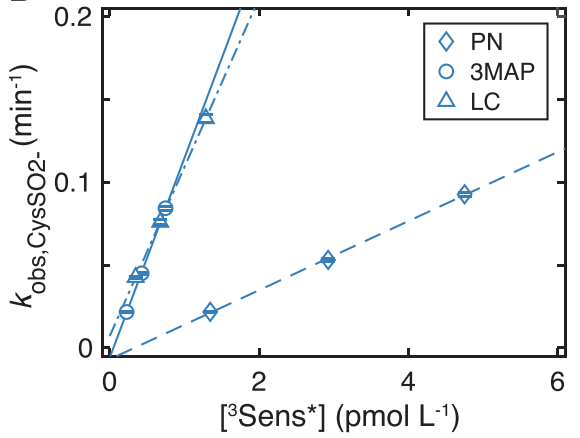

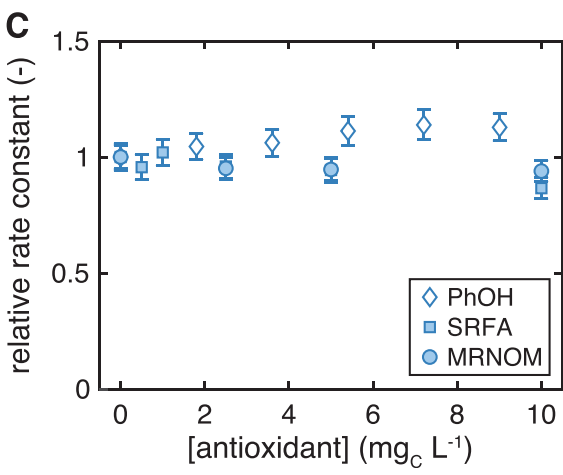

Figure 3. A. Representative $\mathrm{CysSO}_{2}^{-}$photodegradation kinetics in the presence of $3 \mathrm{MAP}\left(20 \mu \mathrm{mol} \mathrm{L}{ }^{-1}\right)$ at $\mathrm{pH}$ 7.3. Each data point is a single experimental concentration, and lines are the results of global fits (eqs 1-3) of experimental data pooled from four independent replicates. B. Plot of the pseudo-first-order $\mathrm{CysSO}_{2}{ }^{-}$degradation rate constant $\left(k_{\mathrm{obs}, \mathrm{Cys} \mathrm{SO}_{2}}{ }^{-}\right)$as a function of the triplet steady-state concentration for three model sensitizers. Each rate constant is obtained from a global fit of data pooled from at least duplicate experiments, and errors are standard errors of the fit. $\left[{ }^{3} \mathrm{Sens} *\right]_{\mathrm{ss}}$ are calculated from $\left[{ }^{1} \mathrm{O}_{2}\right]_{\mathrm{ss}}$ data obtained via FFA depletion kinetics; errors are not indicated. C. Relative $\mathrm{CysSO}_{2}{ }^{-}$degradation rate constant (i.e., $k_{\mathrm{obs}, \mathrm{CysSO}}{ }_{2}^{-} / k_{\mathrm{obs}, \mathrm{CysSO}}^{[\mathrm{antixidat}]=0}$ ) as a function of the antioxidant concentration. Each rate constant is obtained from a global fit of data pooled from at least duplicate experiments, and errors are propagated from standard errors of the fit. Natural and model antioxidants are indicated with filled and empty symbols, respectively.

water $\left(k_{\mathrm{obs}, \mathrm{CysSO}}^{80 \% \mathrm{D}_{2} \mathrm{O}} / k_{\mathrm{obs}, \mathrm{CysSO}}{ }^{-}=0.92 \pm 0.02\right.$; uncertainty is propagated from the standard error of the fitting parameters), even though $\left[{ }^{1} \mathrm{O}_{2}\right]_{s s}$ increased as expected $\left(\left[{ }^{1} \mathrm{O}_{2}\right]_{s s}^{80 \% \mathrm{D}_{2} \mathrm{O}} /\left[{ }^{1} \mathrm{O}_{2}\right]_{\mathrm{ss}}^{0 \% \mathrm{D}_{2} \mathrm{O}}=4.9 \pm 0.3\right)$.

As an additional test, we executed a photodegradation experiment using a water-soluble zinc porphyrin, $\mathrm{Zn}(\mathrm{TMPyP})$, as the model sensitizer. This compound has a low excited state reduction potential $\left(E^{0 *}=0.78 \mathrm{~V}_{\mathrm{NHE}}\right)^{45}$ and has been shown to act as an essentially pure photochemical source of ${ }^{1} \mathrm{O}_{2} \cdot{ }^{22} \mathrm{We}$ performed a first experiment using relatively low sensitizer concentrations $\left(2 \mu \mathrm{mol} \mathrm{L} \mathrm{L}^{-1}, \mathrm{pH}=7.3\right)$, which yielded an experimental $\left[{ }^{1} \mathrm{O}_{2}\right]_{\mathrm{ss}}$ of $(5.5 \pm 0.3) \mathrm{pmol} \mathrm{L}^{-1}$. Under these conditions, only $6 \%$ of the initial $\mathrm{CysSO}_{2}{ }^{-}$was degraded after $2 \mathrm{~h}$ of irradiation (Figure S9B). As a comparison, in the presence of 3MAP (experimental $\left[{ }^{1} \mathrm{O}_{2}\right]_{\mathrm{ss}}=(0.88 \pm 0.06)$ pmol $\left.\mathrm{L}^{-1}, E^{0 *}=1.64 \mathrm{~V}_{\mathrm{SHE}}{ }^{42}\right), \mathrm{CysSO}_{2}^{-}$was completely degraded in less than $30 \mathrm{~min}$ (Figure $3 \mathrm{~A}$ ). Based on these and other experiments, we estimate the singlet oxygen bimolecular rate constant for $\mathrm{CysSO}_{2}{ }^{-}$to be in the range of $3-7 \times 10^{6} \mathrm{~L} \mathrm{~mol}^{-1}$ $\mathrm{s}^{-1}$ (section $\left.\mathrm{S} 10.1-2\right)$. Using $k_{\mathrm{obs}, \mathrm{CysSO}_{2}}{ }^{-}$and the steady-state concentrations relative to the 3MAP-sensitized experiment, we estimated that ${ }^{1} \mathrm{O}_{2}$ contributes less than $1 \%$ to the overall photochemical reactivity observed in Figure 3A (section S10.3).

This conclusion contrasts the results from Pecci et al., ${ }^{16}$ who reported an increase in oxygen consumption (and not $\mathrm{CysSO}_{2}{ }^{-}$degradation) when the reaction was performed in $\mathrm{D}_{2} \mathrm{O}$. We have not identified the source of discrepancy but are convinced from our data that ${ }^{1} \mathrm{O}_{2}$ is not significantly involved in $\mathrm{CysSO}_{2}{ }^{-}$degradation when $3 \mathrm{MAP}$ is the sensitizer. Based on the results with other sensitizers (see the next section) and on the $E^{0 *}$ of $\mathrm{MB}\left(1.50 \mathrm{~V}_{\mathrm{SHE}}\right){ }^{42}$ we expect that the same holds valid also for methylene blue.

The Role of Triplet Excited States. To investigate further the role of triplet excited states, we performed a series of experiments using sensitizers of various excited state redox potentials $\left(E^{0 *}\right)$ and singlet oxygen quantum yields $\left(\Phi_{\Delta}\right)$. Specifically, we selected perinaphthenone $\left(\mathrm{PN} ; E^{0 *}=1.03\right.$ $\left.\mathrm{V}_{\mathrm{SHE}}, \Phi_{\Delta}=0.98\right),{ }^{42}$ 3MAP $\left(E^{0 *}=1.64 \mathrm{~V}_{\mathrm{SHE}}, \Phi_{\Delta}=0.27\right),{ }^{42}$ and lumichrome $\left(\mathrm{LC} ; E^{0 *}=1.91 \mathrm{~V}_{\mathrm{SHE}}, \Phi_{\Delta}=0.63\right),{ }^{42}$ which are common model sensitizers in environmental chemistry and span the estimated $E^{0 *}$ range for DOM. ${ }^{42}$

The results of these experiments reinforce the conclusions of the previous section that both $\mathrm{CysSO}_{3}{ }^{-}$and $\mathrm{SO}_{4}{ }^{2-}$ are produced via triplet-induced oxidations. The strongest piece of evidence comes from the products yields, which are constant regardless of the sensitizer used or its concentration (Figure S12; average values with their standard deviation $(N=9)$ : $\Phi_{\text {sulfate }}=0.68 \pm 0.02 ; \Phi_{\mathrm{Cys}_{3}{ }^{-}}=0.19 \pm 0.02$ ). Product yields are obtained from the kinetic fit and are defined as $k_{\mathrm{i}} / k_{\text {tot }}$ where $k_{\mathrm{i}}$ is the rate constant connecting $\mathrm{CysSO}_{2}{ }^{-}$to product $i$, and $k_{\text {tot }}$ is the sum of the rate constants of all processes leading from $\mathrm{CysSO}_{2}{ }^{-}$. Since the selected sensitizers have different $\left[{ }^{1} \mathrm{O}_{2}\right]_{\mathrm{ss}} /\left[{ }^{3} \mathrm{Sens}{ }^{*}\right]_{\mathrm{ss}}$ ratios, different product yields would be anticipated if ${ }^{1} \mathrm{O}_{2}$ and ${ }^{3}$ Sens* were responsible for the formation of $\mathrm{CysSO}_{3}{ }^{-}$and sulfate, respectively.

Furthermore, linear correlations were obtained between $k_{\mathrm{obs}, \mathrm{CysSO}_{2}}{ }^{-}$and $\left[{ }^{3} \mathrm{Sens}{ }^{*}\right]_{\mathrm{ss}}$ (Figure $3 \mathrm{~B}$ ), suggesting that the degradation process responsible for the disappearance of the parent compound is a triplet-mediated oxidation. From the slope of the graphs, we obtained bimolecular quenching rate constants of $(3.48 \pm 0.09) \times 10^{8} \mathrm{~L} \mathrm{~mol}^{-1} \mathrm{~s}^{-1},(1.70 \pm 0.01) \times$ $10^{9} \mathrm{~L} \mathrm{~mol}^{-1} \mathrm{~s}^{-1}$, and $(2.01 \pm 0.03) \times 10^{9} \mathrm{~L} \mathrm{~mol}^{-1} \mathrm{~s}^{-1}$ for PN, $\mathrm{LC}$, and 3MAP, respectively. For LC and 3MAP, the sensitizers with the higher $E^{0 *}$, the bimolecular rate constants are close to the diffusion-controlled limit and comparable with, albeit slightly lower than, the literature value for $\mathrm{OH}^{\bullet}\left(k_{\mathrm{rxn}, \mathrm{OH}_{\bullet}}^{\mathrm{CysSO}^{-}}=3.2\right.$ $\times 10^{9}$ to $4.5 \times 10^{9} \mathrm{~L} \mathrm{~mol}^{-1} \mathrm{~s}^{-1} ;{ }^{46,47} E_{\mathrm{OH} \bullet / \mathrm{H}_{2} \mathrm{O}}^{0}=2.32 \mathrm{~V}_{\mathrm{SHE}}$ at $\mathrm{pH} 7^{48}$ ). The PN rate constant is significantly lower than the other sensitizers, which is consistent with its lower $E^{0 *}$, but still in the range of highly reactive compounds. The relatively good match between the bimolecular rate constants and the reduction potential of model triplets and the hydroxyl radical (Figure S13) is consistent with a common mechanism for the rate-determining step. In the case of $\mathrm{OH}^{\bullet}$, a one-electron oxidation of the sulfinyl lone pair to form a sulfinyl radical has been proposed. ${ }^{17}$

The Role of Naturally Occurring Antioxidants. $\mathrm{CysSO}_{2}{ }^{-}$photodegradation was also investigated in the presence of model and natural antioxidants to test for the 
presence of radical repair mechanisms that might be relevant in the natural environment. When using SRFA or MRNOM as natural antioxidants, ${ }^{49}$ we observed a small decrease in $k_{\mathrm{obs}, \mathrm{Cys} \mathrm{SO}_{2}}{ }^{-}\left(-13( \pm 5) \%\right.$ and $-6( \pm 4) \%$ for $10 \mathrm{mg}_{\mathrm{C}} \mathrm{L}^{-1}$ SRFA and MRNOM, respectively) and no changes in the product yields compared to the unamended 3MAP-sensitized experiment (Figures $3 \mathrm{C}$ and S14, filled symbols). Note that, due to the high reactivity of ${ }^{3} 3 \mathrm{MAP}^{*}$, in these experiments DOM is acting solely as an antioxidant, not as the sensitizer. By contrast, when using phenol $(\mathrm{PhOH})$ as a model antioxidant, we found a small increase in $k_{\mathrm{obs}, \mathrm{CysSO}_{2}}{ }^{-}(+13( \pm 6) \%$ for 125 $\mu \mathrm{mol} \mathrm{L}{ }^{-1}$ ) and a small change in the product yields (Figures 3C and S14, empty symbols). These trends suggest that phenol, or one of its degradation products, is inducing further reactivity on the substrate (in addition to ${ }^{3}$ Sens*), rather than (or in addition to) acting as an antioxidant.

Other authors showed a large inhibition in the photodegradation of various compounds at $\mathrm{PhOH}$ concentrations as low as $10 \mu \mathrm{mol} \mathrm{L}-1\left(\approx 0.72 \mathrm{mg}_{\mathrm{C}} \mathrm{L}^{-1}\right),{ }^{2,50}$ which is lower than the smallest concentration that we tested $\left(25 \mu \mathrm{mol} \mathrm{L}^{-1}, \approx 1.80\right.$ $\left.\mathrm{mg}_{\mathrm{C}} \mathrm{L}^{-1}\right)$. Furthermore, others reported evident quenching when using DOM as the antioxidant in the concentration range 2.5-10 $\mathrm{mg}_{\mathrm{C}} \mathrm{L}^{-1}$. $^{51}$ Thus, if sulfinyl radical repair were an efficient process, our experimental conditions would be

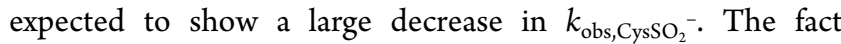
that this decrease is not detected is consistent with the sulfinyl radical being further degraded before it can be repaired by electron donors present in solution.

The Role of Ground State Oxygen. As a further confirmation on the role of triplets, we conducted an experiment under anoxic conditions, where ${ }^{1} \mathrm{O}_{2}$ production was suppressed and $\left[{ }^{3} \text { Sens }{ }^{*}\right]_{\mathrm{ss}}$ was enhanced. Here, $k_{\mathrm{obs}, \mathrm{CysSO}_{2}}{ }^{-}$ increased approximately 2 -fold compared to air-equilibrated solutions, supporting the involvement of triplets in the degradation of the parent compound. Unfortunately, we could not accurately determine the value of the rate constant, as the degradation kinetics deviated from first-order shortly after the beginning of the irradiation (Figure 4A). Additional measurements confirmed that the change in kinetics was caused by photobleaching of the sensitizer (Figure S15), a process that occurs only in the absence of electron acceptors, such as $\mathrm{O}_{2}$.

Under anoxic conditions, we observed only sulfite/bisulfite (indicated also as $\mathrm{S}(\mathrm{IV})$, as at $\mathrm{pH} 7.3$ both species are present in solution, see Figure S3D; $\left.\Phi_{\mathrm{S}(\mathrm{IV})} \approx 70 \%\right)$ and sulfate $\left(\Phi_{\text {sulfate }}\right.$ $\approx 30 \%)$ as the reaction products, which together accounted for $\approx 95 \%$ of the degraded mass (Figure $4 \mathrm{~A}$ ). Further experiments showed that S(IV) is not stable in the dark, implying that the sulfate detected in our experiments may not be a photochemical product of the reaction (section S14.1 and Figure S16). $\mathrm{CysSO}_{3}{ }^{-}$was not formed in the absence of $\mathrm{O}_{2}$, in agreement with the results of the biochemistry studies. ${ }^{16,17}$

We then conducted a reoxygenation experiment to confirm that $S$ (IV) is the precursor of sulfate in the presence of oxygen. The leftover samples after anoxic irradiation were pooled together ( $1 \mathrm{~h}$ irradiation only), amended with $3 \mathrm{MAP}(20 \mu \mathrm{mol}$ $\left.\mathrm{L}^{-1}\right)$ to replenish the sensitizer pool, sparged with compressed air, and irradiated with UVB light for an additional hour. As shown in Figure 4A, the sulfite/bisulfite formed in anoxic conditions was converted quantitatively into sulfate, confirming its competence as a reaction intermediate. Control experiments confirmed that light, oxygen, and a sensitizer
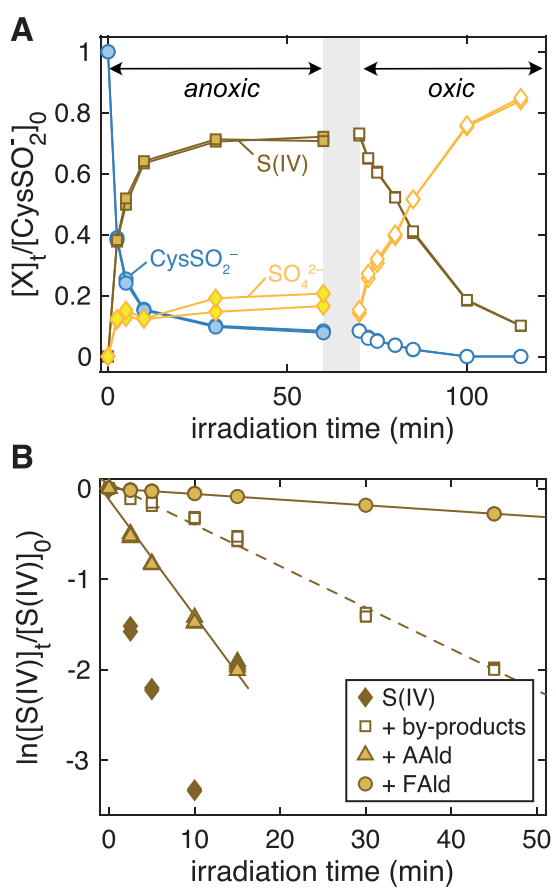

Figure 4. A. Reoxygenation experiment (anoxic: [3MAP] $=30 \mu \mathrm{mol}$ $\mathrm{L}^{-1}, \mathrm{pH}=7.3,6 \times \mathrm{UVB}$, filled symbols; oxic: [3MAP] $=20 \mu \mathrm{mol} \mathrm{L}^{-1}$, $\mathrm{pH}=7.3,6 \times \mathrm{UVB}$, open symbols). $\mathrm{CysSO}_{3}{ }^{-}$formed from $\mathrm{CysSO}_{2}{ }^{-}$ during oxic irradiation is not indicated $(<1 \%)$. Each symbol is a single concentration (error bars not indicated); lines are added for the sake of clarity and are not global fits. B. Effects of solution components on $\mathrm{S}(\mathrm{IV})$ photodegradation kinetics in the presence of 3MAP $(20 \mu \mathrm{mol}$ $\mathrm{L}^{-1}, \mathrm{pH}$ 7.3; FAld, formaldehyde; AAld, acetaldehyde). Open squares are the same experimental data of panel A (oxic) plotted in logarithmic scale. Lines are linear regressions of the experimental points $\left(R^{2}>0.9\right)$.

need to be present to trigger the conversion of S(IV) to sulfate (section S14.2 and Figure S17). We also estimated the S(IV) degradation rate constant to be on the same order of magnitude as observed for $\mathrm{CysSO}_{2}{ }^{-}$, i.e., $k_{\mathrm{obs}, \mathrm{CysSO}}{ }_{2}^{-} / k_{\mathrm{obs}, \mathrm{S}(\mathrm{IV})}$ $=2.23 \pm 0.07\left(k_{\mathrm{obs}, \mathrm{CysSO}_{2}}{ }^{-}\right.$was estimated from the decay of the residual $\mathrm{CysSO}_{2}{ }^{-}$peak in the oxic phase).

Sulfite Degradation Kinetics. To further establish the presence of a photosensitized mechanism for the oxidation of S(IV), we irradiated a freshly prepared solution of sodium sulfite in the presence of $3 \mathrm{MAP}\left(20 \mu \mathrm{mol} \mathrm{L}^{-1}, \mathrm{pH} 7.3-7.4\right)$, and we characterized its degradation kinetics. Surprisingly, S(IV) disappeared completely within the first $10 \mathrm{~min}$ of irradiation (Figure 4B, filled diamonds) in a process that did not strictly obey pseudo-first-order kinetics. By following $\mathrm{CysSO}_{2}{ }^{-}$degradation in a separate test tube under the exact same conditions (in terms of light intensity, $\mathrm{pH}$, and [3MAP]), we estimated $k_{\mathrm{obs}, \mathrm{CysSO}}{ }_{2}^{-} / k_{\mathrm{obs}, \mathrm{S}(\mathrm{IV})}=0.122 \pm 0.006$, which is almost 20 times smaller than in the reoxygenation experiment.

Early studies reported evidence of a radical chain mechanism during photosensitized S(IV) degradation in the presence of various dyes, including methylene blue, Rose Bengal, and chlorophyll, among others. ${ }^{52-56}$ This same radical chain mechanism has also been observed in other S(IV)-related processes, including metal-catalyzed reactions, direct photolysis, enzymatic reactions, and electrolytic processes. ${ }^{57,58}$ The presence of a radical chain mechanism fits well with the considerably faster S(IV) photodegradation observed in the 

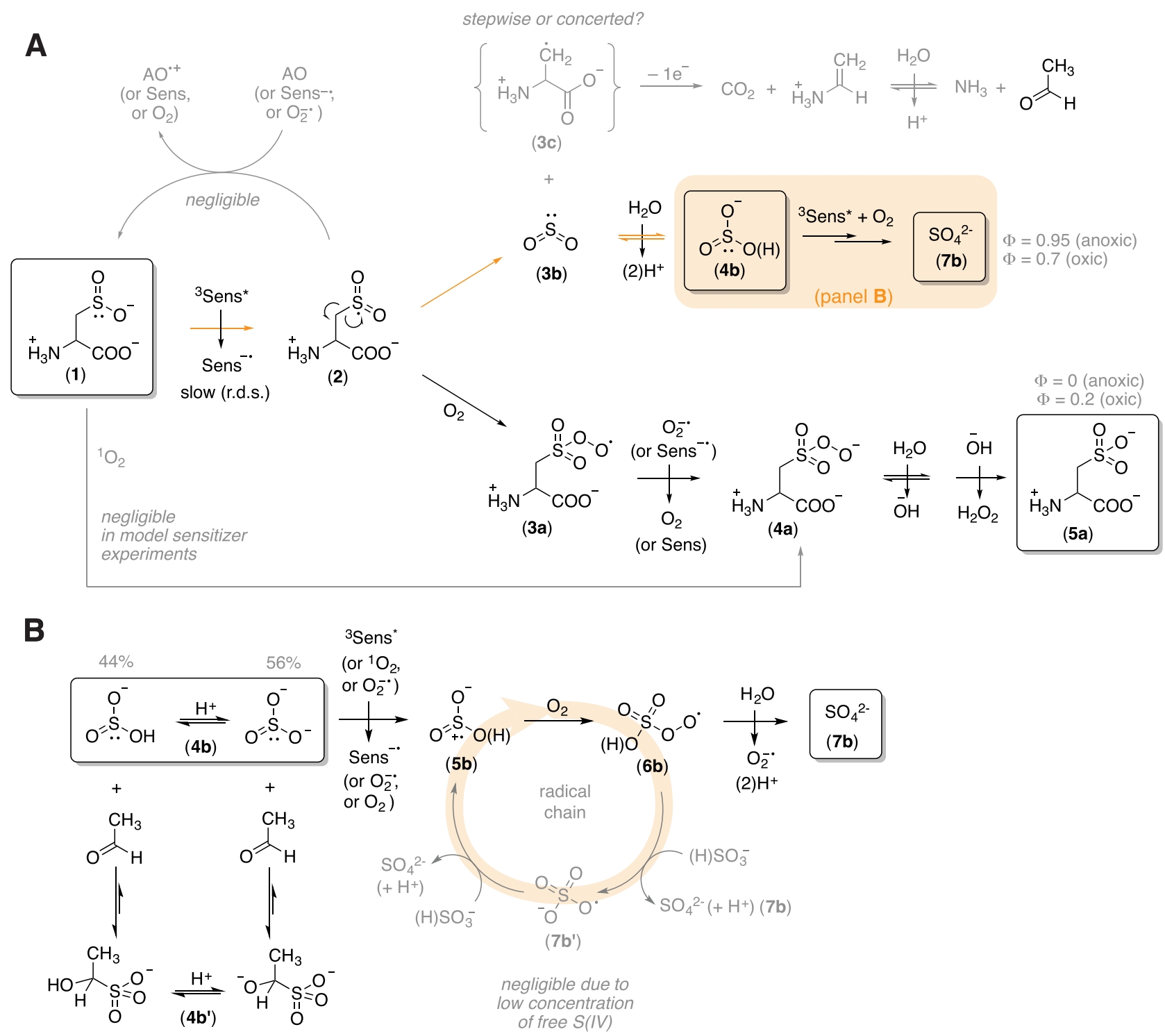

Figure 5. A. Proposed $\mathrm{CysSO}_{2}^{-}$(1) photodegradation mechanism based on the available biochemistry literature and the results of our photochemistry experiments. Arrows in orange indicate the reaction pathway isolated when performing the experiment in anoxic conditions. Blackframed boxes highlight compounds that were identified and measured via IC. B. Proposed photosensitized S(IV) oxidation mechanism in the presence of acetaldehyde (highlighted in panel A with an orange box). At the experimental $\mathrm{pH}$ of $7.2,44 \%$ of $\mathrm{S}$ (IV) is present as bisulfite, and $56 \%$ is present as sulfite (Figure S3D). Note that this is only one of the S(IV) inhibition mechanisms active in our system.

presence of 3MAP alone compared to a solution containing $3 \mathrm{MAP}, \mathrm{CysSO}_{2}^{-}$, and their degradation products. Indeed, inhibition in the presence of organics has been used as a diagnostic test for radical chain mechanisms. ${ }^{52,59}$

This interpretation led us to the hypothesis that $\mathrm{CysSO}_{2}{ }^{-}$or one of its degradation products inhibited S(IV) oxidation during the reoxygenation experiment. It is well-known that organic molecules such as aldehydes, alcohols, sugars, and organic acids can act as $\mathrm{S}(\mathrm{IV})$ preservatives. ${ }^{20,21,58-62}$ In particular, aldehydes are known to react chemically with sulfite forming hydroxyalkylsulfonates, inert compounds that can act as $\mathrm{S}$ (IV) reservoirs. ${ }^{60}$ Another way in which organics can act as inhibitors is by scavenging the sulfate radical $\left(\mathrm{SO}_{4}{ }^{--}\right)$, an extremely strong oxidant formed during the propagation stage of the radical chain. ${ }^{58}$ From the work of Pecci et al., ${ }^{16}$ we knew that the liberation of $\mathrm{SO}_{2}$ from $\mathrm{CysSO}_{2}{ }^{-}$triggers complete destruction of the molecule with the formation of $\mathrm{CO}_{2}, \mathrm{NH}_{4}^{+}$, and acetaldehyde in equimolar amounts. From these observations, we reasoned that acetaldehyde could act as an inhibitor of the radical chain process, explaining the slow and well-behaved first-order kinetics.

Figure $4 \mathrm{~B}$ shows the effects of addition of $1 \mathrm{~mol} / \mathrm{mol}_{\mathrm{S} \text { (IV) }}$ of acetaldehyde (triangles) and formaldehyde (circles; used as an aldehyde model) on 3MAP-sensitized S(IV) oxidation. Compared to the unamended sample, both aldehydes slowed down S(IV) degradation kinetics and made it pseudo-firstorder. Notably, acetaldehyde had a milder effect compared with formaldehyde, which can be justified in terms of differences in hydroxyalylsulfonate stability constants. ${ }^{60} \mathrm{We}$ found that $1 \mathrm{~mol} / \mathrm{mol}_{\mathrm{S}(\mathrm{IV})}$ of acetaldehyde could not explain the quenching effect observed in the presence of $\mathrm{CysSO}_{2}^{-}$ byproducts, suggesting that additional matrix components present during the reoxygenation experiment might further inhibit S(IV) degradation. A likely possibility is that also $3 \mathrm{MAP}$, which is completely photodegraded under anoxic conditions (Figure S15), can produce acetaldehyde, other 
aldehydes, or other S(IV) quenchers. To test this hypothesis, we investigated the effect of increased acetaldehyde concentrations $\left(2-10 \mathrm{~mol} / \mathrm{mol}_{\mathrm{S}(\mathrm{IV})}\right.$; Figure $\left.\mathrm{S} 18 \mathrm{~B}\right)$ and of the simultaneous presence of formaldehyde and acetaldehyde (Figure S18C) on S(IV) degradation kinetics, and in both cases, we observed additional inhibition compared to $1 \mathrm{~mol} /$ mol $_{\text {S(IV) }}$ acetaldehyde. We also attempted to generate a sensitizer product mixture by irradiating a 3MAP solution kept under argon, but we found that the sensitizer is photochemically stable in the absence of $\mathrm{CysSO}_{2}^{-}$(Figure $\mathrm{S} 15 \mathrm{~B})$. An alternative explanation is that our amendment experiments do not reproduce accurately the conditions of the reoxygenation experiment because, in circumneutral solutions, small variations in $\mathrm{pH}$ have a considerable effect in the speciation of $\mathrm{S}(\mathrm{IV})$ also in the presence of a buffer (i.e., at $\mathrm{pH}$ $7.2, \mathrm{SO}_{3}{ }^{2-}$ is $51 \%$, while, at $\mathrm{pH} 7.4, \mathrm{SO}_{3}{ }^{2-}$ is $64 \%$; Figure $\mathrm{S} 3 \mathrm{D}$ ).

Proposed Reaction Mechanism. Based on our experimental results, we propose that both $\mathrm{CysSO}_{2}^{-}$products, sulfate and $\mathrm{CysSO}_{3}{ }^{-}$, are formed via triplet-induced oxidations according to the mechanism illustrated in Figure 5A. Specifically, in the presence of ${ }^{3} \mathrm{Sens} *, \mathrm{CysSO}_{2}{ }^{-}(\mathbf{1})$ is oxidized to the cysteine sulfinyl radical $\left(\mathrm{CysSO}_{2}{ }^{\circ}, 2\right)$. One-electron oxidation is also the proposed mechanism for $\mathrm{OH}^{\bullet},{ }^{17}$ in agreement with the trends that we observed in the bimolecular rate constants (Figure S13). The sulfinyl radical is unstable in both oxic and anoxic conditions and undergoes further degradation before it can be repaired by any electron donor present in solution, i.e., the reduced sensitizer $\left(\mathrm{Sens}^{\bullet-}\right)$, superoxide radical anions $\left(\mathrm{O}_{2}{ }^{\bullet-}\right)$, and natural or model antioxidants. The fate of $\mathrm{CysSO}_{2}{ }^{\cdot}$ is influenced by $\mathrm{O}_{2}$ levels. Under air-saturated conditions, $\approx 20 \%$ of the radical reacts with $\mathrm{O}_{2}$ to form the cysteine sulfonyl peroxide radical (3a), which accepts an electron to become a sulfonyl peroxide (4a). Intermediate 4a can also form via ${ }^{1} \mathrm{O}_{2}$ attack on the sulfinic acid moiety, but this process becomes relevant only in the absence of other oxidants. Hydration and hydrolysis convert 4a into the final product, $\mathrm{CysSO}_{3}{ }^{-}$(5a). Cysteine sulfonic acid can also form directly from hydrolysis of 3a. Note that steps from 2 to 5 a are very similar to the ones proposed for biological oxidants. ${ }^{17}$ Alternatively, 2 undergoes a C-S bond cleavage to release $\mathrm{SO}_{2}(3 \mathbf{b})$, which becomes hydrated to yield $\mathrm{S}(\mathrm{IV})(\mathbf{4 b})$. In the absence of oxygen, this reaction occurs with almost unitary yield, while, under oxic conditions, $\Phi_{\mathrm{S}(\mathrm{IV})} \approx$ 0.70. Acetaldehyde, $\mathrm{CO}_{2}$, and $\mathrm{NH}_{4}^{+}$were previously reported as reaction coproducts under oxic and anoxic conditions, ${ }^{16}$ suggesting that $\mathrm{C}-\mathrm{S}$ bond cleavage is associated with extensive degradation of the molecule.

Under oxic conditions and in the presence of a sensitizer, $\mathrm{S}(\mathrm{IV})$ is readily oxidized to sulfate ( $7 \mathbf{b}$; Figure $5 \mathrm{~B})$. In the absence of inhibitors, this process occurs via the same radical chain mechanism that has been described for other oxidants. There is currently a lack of consensus on the nature of the initiation step in photosensitized S(IV) oxidation, which has been proposed to be triggered by ${ }^{1} \mathrm{O}_{2}, \mathrm{O}_{2}{ }^{\bullet-}$, or ${ }^{3}$ Sens*. ${ }^{52,56,63-65}$ A few authors observed evidence of triplet quenching by $S(I V),{ }^{63-66}$ but at the current state of knowledge, we cannot exclude other mechanisms. Sulfite/ bisulfite oxidation leads to the formation of sulfite radical (5b), which reacts with $\mathrm{O}_{2}$ to form the sulfite peroxo radical $(\mathbf{6 b})$. 6b can then react with $S$ (IV) to establish the radical chain, which leads to the formation of sulfate radicals $\left(\mathbf{7} \mathbf{b}^{\prime}\right)$ and sulfate $(\mathbf{7 b})$. In the presence of acetaldehyde, $S(I V)$ is trapped into a hydroxymethylsulfonate adduct $\left(\mathbf{4 b ^ { \prime } )}\right.$ that is stable toward both oxidation and dissociation. At any given time, only a small fraction of S(IV) is present in a dissociated (reactive) form, resulting in the deactivation of all propagation processes due to a lack of reactants (i.e., S(IV)). In this case, sulfate can be generated from hydrolysis of the sulfite peroxo radical $(6 \mathbf{b})$.

\section{ENVIRONMENTAL IMPLICATIONS}

In this work, we showed that triplet-sensitized $\mathrm{CysSO}_{2}{ }^{-}$ oxidation releases $\mathrm{SO}_{4}{ }^{2-}$ via a process that involves the reaction sequence $\mathrm{SO}_{2} \rightleftharpoons \mathrm{S}(\mathrm{IV}) \rightarrow \mathrm{SO}_{4}{ }^{2-}$ ( $3 \mathbf{b}$ to $7 \mathbf{b}$ in Figure $5)$. Even if we showed that S(IV) oxidation is impacted by reaction byproducts, which can be substrate-dependent, we argue that this short reaction sequence represents a "general" sulfate formation pathway that is valid independent of the structure of the model compound. Indeed, any other substrate that can liberate $\mathrm{SO}_{2}$ via photosensitized degradation or direct photolysis will produce sulfate via an analogous mechanism. For example, sulfonamide antibiotics, a class of pollutants ubiquitous in the environment, ${ }^{67}$ are known to undergo $\mathrm{SO}_{2}$ extrusion via direct and indirect photolysis, ${ }^{68-70}$ sulfate radicalmediated oxidation, ${ }^{71-73}$ and other oxidation processes. ${ }^{7-77}$ In particular, $\mathrm{SO}_{2}$ extrusion was proposed to be the primary photodegradation route for five six-membered sulfonamides, ${ }^{6}$ and sulfate was reported among the photoproducts. ${ }^{69}$ Photoinduced extrusion of $\mathrm{SO}_{2}$ from organic sulfones is also exploited in synthetic organic chemistry as a mild route to form new $\mathrm{C}-\mathrm{C}$ bonds, both via direct (requiring a chromophore $\beta$ to the sulfone) and triplet-induced photolysis. ${ }^{78,79}$ Unfortunately, the organic chemistry literature is limited to reactions performed in organic solvents and with the specific aim of obtaining highly unstable ring structures for further synthetic transformations. ${ }^{79}$ Further research is needed to assess whether natural sulfones and other DOS components can liberate $\mathrm{SO}_{2}$ upon photolysis under environmentally relevant conditions.

Besides sulfate, our work can also indirectly provide insight into the formation mechanism of other photoproducts. Specifically, $\mathrm{NH}_{4}^{+}, \mathrm{CO}_{2}$, and acetaldehyde, which are all known DOM photoproducts, ${ }^{3,4}$ can be formed from photosensitized $\mathrm{CysSO}_{2}{ }^{-}$degradation during the process that leads to release $\mathrm{SO}_{2} .{ }^{16}$ Tarr et al. ${ }^{6}$ already reported ammonia as a DOM-sensitized photodegradation product of tryptophan, methionine, tyrosine, and L-3,4-dihydroxyphenylalanine. Our work may provide a clue to at least one photochemical mechanism for $\mathrm{NH}_{4}^{+}$production from amino acids, as it suggests that ammonia can be released as a result of a fragmentation triggered by an oxidizable (or photolabile) group in the $\beta$ position. This interpretation can explain why glycine was found to be unable to release $\mathrm{NH}_{4}{ }^{+} \cdot{ }^{6}$ Furthermore, to the authors' knowledge, acetaldehyde has never been proposed to be formed from the photodegradation of amino acids in the context of DOM photoproducts. Further work is needed to investigate whether amino acids in general, which are also known DON photodegradation products, ${ }^{4,6}$ can be environmentally relevant precursors of this low-molecularweight carbonyl compound. Additionally, we showed that hydrogen peroxide, a reactive species with relatively long lifetimes present in sunlit surface waters, ${ }^{80}$ can be formed from the hydrolysis of organic peroxides. According to the common consensus, $\mathrm{H}_{2} \mathrm{O}_{2}$ is formed from the dismutation of $\mathrm{O}_{2}^{\bullet-80,81}$ even if several lines of evidence showed that a significant 
amount of $\mathrm{O}_{2}{ }^{\bullet-}$ decays via other pathways that do not form hydrogen peroxide. ${ }^{80}$

\section{ASSOCIATED CONTENT}

\section{SI Supporting Information}

The Supporting Information is available free of charge at https://pubs.acs.org/doi/10.1021/acs.est.0c04340.

Overview of mechanistic studies on DOM photoproducts; supplementary details of photochemistry experiments, control experiments, and lamp emission spectra; compounds speciation at $\mathrm{pH} 7.2$; determination of $\mathrm{pK}_{\mathrm{a}}$ values of cysteine sulfinic acid via ${ }^{1} \mathrm{H}-\mathrm{NMR}$; controls of possible sulfite interferences during IC analyses; estimation of $\left[{ }^{3} \text { Sens }{ }^{*}\right]_{\text {ss }}$ using experimental $C^{\prime}$ values; additional sulfate photoproduction pathways from cysteine; kinetic models; additional experiments to test role of ${ }^{1} \mathrm{O}_{2}$; control experiment for anoxic conditions and for reoxygenation experiment; supplementary graphs for experiments testing role of ${ }^{1} \mathrm{O}_{2}$, ${ }^{3}$ Sens*, antioxidants, and oxygen on $\mathrm{CysSO}_{2}{ }^{-}$photodegradation; additional experiments to test role of aldehydes on triplet-sensitized S(IV) degradation (PDF)

\section{AUTHOR INFORMATION}

\section{Corresponding Author}

Kristopher McNeill - Institute of Biogeochemistry and Pollutant Dynamics (IBP), Department of Environmental Systems Science, ETH Zurich, 8092 Zurich, Switzerland; (ㄷ) orcid.org/0000-0002-2981-2227; Email: kris.mcneill@ env.ethz.ch

\section{Authors}

Rachele Ossola - Institute of Biogeochemistry and Pollutant Dynamics (IBP), Department of Environmental Systems Science, ETH Zurich, 8092 Zurich, Switzerland; (1) orcid.org/ 0000-0003-4648-5958

Baptiste Clerc - Institute of Biogeochemistry and Pollutant Dynamics (IBP), Department of Environmental Systems Science, ETH Zurich, 8092 Zurich, Switzerland

Complete contact information is available at: https://pubs.acs.org/10.1021/acs.est.0c04340

\section{Author Contributions}

R.O. and K.M. designed the experiments. R.O. and B.C. performed the photolysis experiments, the chemical analyses, and the literature review. R.O. analyzed the data and wrote the manuscript with contributions from all authors.

\section{Funding}

The authors gratefully acknowledge funding for this project from ETH Zurich and the Swiss National Science Foundation (grant number 200020_188565).

\section{Notes}

The authors declare no competing financial interest.

\section{ACKNOWLEDGMENTS}

The authors acknowledge Gordon Getzinger for insightful discussions and Saskia Läubli for her contribution to the project.

\section{ABBREVIATIONS}

$C^{\prime}$, ratio of ${ }^{1} \mathrm{O}_{2}$ to ${ }^{3} \mathrm{Sens} *$ steady-state concentrations; $\mathrm{CysSO}_{2}{ }^{-}$, cysteine sulfinate; $\mathrm{CysSO}_{3}{ }^{-}$, cysteine sulfonate; DOM, dissolved organic matter; DOS, dissolved organic sulfur; $E^{0 *}$, excited state reduction potential (of a sensitizer); FFA, furfuryl alcohol; LC, lumichrome; 3MAP, 3'-methoxyacetophenone; ${ }^{1} \mathrm{O}_{2}$, singlet oxygen; $\mathrm{MB}$, methylene blue; MRNOM, Mississippi River natural organic matter; $\mathrm{PhOH}$, phenol; PN, perinaphthenone; S(IV), sulfite/bisulfite; SRFA, Suwannee River fulvic acid; Sens, sensitizer; ${ }^{3}$ Sens*, triplet sensitizer excited state; TMP, 2,4,6-trimethylphenol; Zn(TMPyP), zinc 5,10,15,20-tetra(4-pyridyl)-21H,23H-porphine-tetrakis(methochloride) (water-soluble zinc porphyrin)

\section{REFERENCES}

(1) Sulzberger, B.; Austin, A. T.; Cory, R. M.; Zepp, R. G.; Paul, N. D. Solar UV Radiation in a Changing World: Roles of CryosphereLand-Water-Atmosphere Interfaces in Global Biogeochemical Cycles. Photochem. Photobiol. Sci. 2019, 18 (3), 747-774.

(2) Cory, R. M.; Ward, C. P.; Crump, B. C.; Kling, G. W. Sunlight Controls Water Column Processing of Carbon in Arctic Fresh Waters. Science 2014, 345 (6199), 925-928.

(3) Moran, M. A.; Zepp, R. G. Role of Photoreactions in the Formation of Biologically Labile Compounds from Dissolved Organic Matter. Limnol. Oceanogr. 1997, 42 (6), 1307-1316.

(4) Mopper, K.; Kieber, D. J.; Stubbins, A. Chapter 8 - Marine Photochemistry of Organic Matter: Processes and Impacts A2 Hansell, Dennis A. In Biogeochemistry of Marine Dissolved Organic Matter (2nd ed.); Carlson, C. A., Ed.; Academic Press: Boston, 2015; pp 389-450, DOI: 10.1016/B978-0-12-405940-5.00008-X.

(5) Bushaw, K. L.; Zepp, R. G.; Tarr, M. A.; Schulz-Jander, D.; Bourbonniere, R. A.; Hodson, R. E.; Miller, W. L.; Bronk, D. A.; Moran, M. A. Photochemical Release of Biologically Available Nitrogen from Aquatic Dissolved Organic Matter. Nature 1996, 381 (6581), 404-407.

(6) Tarr, M. A.; Wang, W.; Bianchi, T. S.; Engelhaupt, E. Mechanisms of Ammonia and Amino Acid Photoproduction from Aquatic Humic and Colloidal Matter. Water Res. 2001, 35 (15), 3688-3696

(7) Vähätalo, A. V.; Zepp, R. G. Photochemical Mineralization of Dissolved Organic Nitrogen to Ammonium in the Baltic Sea. Environ. Sci. Technol. 2005, 39 (18), 6985-6992.

(8) Francko, D. A.; Heath, R. T. UV-Sensitive Complex Phosphorus: Association with Dissolved Humic Material and Iron in a Bog Lake1. Limnol. Oceanogr. 1982, 27 (3), 564-569.

(9) Liu, G.; Tang, Q.; Zhou, Y.; Cao, X.; Zhao, J.; Zhu, D. PhotoInduced Phosphate Released from Organic Phosphorus Degradation in Deionized and Natural Water. Photochem. Photobiol. Sci. 2017, 16 (4), 467-475.

(10) Gardolinski, P. C. F. C.; Worsfold, P. J.; McKelvie, I. D. Seawater Induced Release and Transformation of Organic and Inorganic Phosphorus from River Sediments. Water Res. 2004, 38 (3), 688-692.

(11) Andreae, M. O.; Ferek, R. J. Photochemical Production of Carbonyl Sulphide in Marine Surface Waters. Nature 1984, 307 (5947), 148.

(12) Du, Q.; Mu, Y.; Zhang, C.; Liu, J.; Zhang, Y.; Liu, C. Photochemical Production of Carbonyl Sulfide, Carbon Disulfide and Dimethyl Sulfide in a Lake Water. J. Environ. Sci. 2017, 51 (Supplement C), 146-156.

(13) Flöck, O. R.; Andreae, M. O.; Dräger, M. Environmentally Relevant Precursors of Carbonyl Sulfide in Aquatic Systems. Mar. Chem. 1997, 59 (1), 71-85.

(14) Ossola, R.; Tolu, J.; Clerc, B.; Erickson, P. R.; Winkel, L. H. E.; McNeill, K. Photochemical Production of Sulfate and Methanesulfonic Acid from Dissolved Organic Sulfur. Environ. Sci. Technol. 2019, 53 (22), 13191-13200. 
(15) Zhang, X.; Li, J.; Fan, W.-Y.; Sheng, G.-P. Photomineralization of Effluent Organic Phosphorus to Orthophosphate under Simulated Light Illumination. Environ. Sci. Technol. 2019, 53 (9), 4997-5004.

(16) Pecci, L.; Costa, M.; Antonucci, A.; Montefoschi, G.; Cavallini, D. Methylene Blue Photosensitized Oxidation of Cysteine Sulfinic Acid and Other Sulfinates: The Involvement of Singlet Oxygen and the Azide Paradox. Biochem. Biophys. Res. Commun. 2000, 270 (3), $782-786$.

(17) Conrado, A. B.; D’Angelantonio, M.; D’Erme, M.; Pecci, L.; Fontana, M. The Interaction of Hypotaurine and Other Sulfinates with Reactive Oxygen and Nitrogen Species: A Survey of Reaction Mechanisms. In Taurine 10; Advances in Experimental Medicine and Biology; Springer: Dordrecht, 2017; pp 573-583, DOI: 10.1007/97894-024-1079-2 45.

(18) Pos, W. $\bar{H}$.; Riemer, D. D.; Zika, R. G. Carbonyl Sulfide (OCS) and Carbon Monoxide (CO) in Natural Waters: Evidence of a Coupled Production Pathway. Mar. Chem. 1998, 62 (1), 89-101.

(19) Laszakovits, J. R.; Berg, S. M.; Anderson, B. G.; O’Brien, J. E.; Wammer, K. H.; Sharpless, C. M. p-Nitroanisole/Pyridine and $p$ Nitroacetophenone/Pyridine Actinometers Revisited: Quantum Yield in Comparison to Ferrioxalate. Environ. Sci. Technol. Lett. 2017, 4, $11-14$.

(20) Campanella, L.; Majone, M.; Pocci, R. Behaviour of Different Eluents and Stabilizing Agents in the Determination of Sulphite in Water by Ion-Chromatography. Talanta 1990, 37 (2), 201-205.

(21) Lindgren, M.; Cedergren, A.; Lindberg, J. Conditions for Sulfite Stabilization and Determination by Ion Chromatography. Anal. Chim. Acta 1982, 141, 279-286.

(22) Ossola, R.; Schmitt, M.; Erickson, P. R.; McNeill, K. Furan Carboxamides as Model Compounds To Study the Competition between Two Modes of Indirect Photochemistry. Environ. Sci. Technol. 2019, 53 (16), 9594-9603.

(23) Chu, C.; Erickson, P. R.; Lundeen, R. A.; Stamatelatos, D.; Alaimo, P. J.; Latch, D. E.; McNeill, K. Photochemical and Nonphotochemical Transformations of Cysteine with Dissolved Organic Matter. Environ. Sci. Technol. 2016, 50 (12), 6363-6373.

(24) Multiple curve fitting with common parameters using NLINFIT - File Exchange - MATLAB Central. https://www. mathworks.com/matlabcentral/fileexchange/40613 (accessed 201912-10).

(25) Appiani, E.; Ossola, R.; Latch, D. E.; Erickson, P. R.; McNeill, K. Aqueous Singlet Oxygen Reaction Kinetics of Furfuryl Alcohol: Effect of Temperature, PH, and Salt Content. Environ. Sci. Process. Impacts 2017, 19 (4), 507-516.

(26) Stipanuk, M. H.; Ueki, I. Dealing with Methionine/ Homocysteine Sulfur: Cysteine Metabolism to Taurine and Inorganic Sulfur. J. Inherited Metab. Dis. 2011, 34 (1), 17-32.

(27) Alcock, L. J.; Perkins, M. J.; Chalker, J. M. Chemical Methods for Mapping Cysteine Oxidation. Chem. Soc. Rev. 2018, 47 (1), 231268.

(28) Poole, L. B. The Basics of Thiols and Cysteines in Redox Biology and Chemistry. Free Radical Biol. Med. 2015, 80, 148-157.

(29) Lo Conte, M.; Carroll, K. S. The Redox Biochemistry of Protein Sulfenylation and Sulfinylation. J. Biol. Chem. 2013, 288 (37), 26480-26488.

(30) Liem-Nguyen, V.; Bouchet, S.; Björn, E. Determination of SubNanomolar Levels of Low Molecular Mass Thiols in Natural Waters by Liquid Chromatography Tandem Mass Spectrometry after Derivatization with p-(Hydroxymercuri) Benzoate and Online Preconcentration. Anal. Chem. 2015, 87 (2), 1089-1096.

(31) Dupont, C. L.; Moffett James, W.; Bidigare, R. R.; Ahner, B. A. Distributions of Dissolved and Particulate Biogenic Thiols in the Subartic Pacific Ocean. Deep Sea Res., Part I 2006, 53 (12), 19611974.

(32) Hu, H.; Mylon, S. E.; Benoit, G. Distribution of the Thiols Glutathione and 3-Mercaptopropionic Acid in Connecticut Lakes. Limnol. Oceanogr. 2006, 51 (6), 2763-2774.
(33) Tang, D.; Hung, C.-C.; Warnken, K. W.; Santschi, P. H. The Distribution of Biogenic Thiols in Surface Waters of Galveston Bay. Limnol. Oceanogr. 2000, 45 (6), 1289-1297.

(34) Chu, C.; Stamatelatos, D.; McNeill, K. Aquatic Indirect Photochemical Transformations of Natural Peptidic Thiols: Impact of Thiol Properties, Solution pH, Solution Salinity and Metal Ions. Environ. Sci. Process. Impacts 2017, 19 (12), 1518-1527.

(35) Zepp, R. G.; Andreae, M. O. Factors Affecting the Photochemical Production of Carbonyl Sulfide in Seawater. Geophys. Res. Lett. 1994, 21 (25), 2813-2816.

(36) Modiri Gharehveran, M.; Shah, A. D. Indirect Photochemical Formation of Carbonyl Sulfide and Carbon Disulfide in Natural Waters: Role of Organic Sulfur Precursors, Water Quality Constituents, and Temperature. Environ. Sci. Technol. 2018, 52 (16), 9108-9117.

(37) Xie, H.; Moore, R. M.; Miller, W. L. Photochemical Production of Carbon Disulphide in Seawater. J. Geophys. Res. Oceans 1998, 103 (C3), 5635-5644.

(38) Leonard, S. E.; Carroll, K. S. Chemical 'Omics' Approaches for Understanding Protein Cysteine Oxidation in Biology. Curr. Opin. Chem. Biol. 2011, 15 (1), 88-102.

(39) Augusto, O.; Bonini, M. G.; Amanso, A. M.; Linares, E.; Santos, C. C. X.; De Menezes, S. L. Nitrogen Dioxide and Carbonate Radical Anion: Two Emerging Radicals in Biology. Free Radical Biol. Med. 2002, 32 (9), 841-859.

(40) Harman, L. S.; Mottley, C.; Mason, R. P. Free Radical Metabolites of L-Cysteine Oxidation. J. Biol. Chem. 1984, 259 (9), $5606-5611$

(41) Tardivo, J. P.; Del Giglio, A.; de Oliveira, C. S.; Gabrielli, D. S.; Junqueira, H. C.; Tada, D. B.; Severino, D.; de Fátima Turchiello, R.; Baptista, M. S. Methylene Blue in Photodynamic Therapy: From Basic Mechanisms to Clinical Applications. Photodiagn. Photodyn. Ther. 2005, 2 (3), 175-191.

(42) McNeill, K.; Canonica, S. Triplet State Dissolved Organic Matter in Aquatic Photochemistry: Reaction Mechanisms, Substrate Scope, and Photophysical Properties. Environ. Sci. Process. Impacts 2016, 18 (11), 1381-1399.

(43) Erickson, P. R.; Moor, K. J.; Werner, J. J.; Latch, D. E.; Arnold, W. A.; McNeill, K. Singlet Oxygen Phosphorescence as a Probe for Triplet-State Dissolved Organic Matter Reactivity. Environ. Sci. Technol. 2018, 52 (16), 9170-9178.

(44) Davis, C. A.; McNeill, K.; Janssen, E. M.-L. Non-Singlet Oxygen Kinetic Solvent Isotope Effects in Aquatic Photochemistry. Environ. Sci. Technol. 2018, 52 (17), 9908-9916.

(45) Kalyanasundaram, K.; Neumann-Spallart, M. Photophysical and Redox Properties of Water-Soluble Porphyrins in Aqueous Media. J. Phys. Chem. 1982, 86 (26), 5163-5169.

(46) Conrado, A. B.; D’Angelantonio, M.; Torreggiani, A.; Pecci, L.; Fontana, M. Reactivity of Hypotaurine and Cysteine Sulfinic Acid toward Carbonate Radical Anion and Nitrogen Dioxide as Explored by the Peroxidase Activity of $\mathrm{Cu}, \mathrm{Zn}$ Superoxide Dismutase and by Pulse Radiolysis. Free Radical Res. 2014, 48 (11), 1300-1310.

(47) Aruoma, O. I.; Halliwell, B.; Hoey, B. M.; Butler, J. The Antioxidant Action of Taurine, Hypotaurine and Their Metabolic Precursors. Biochem. J. 1988, 256 (1), 251-255.

(48) Wood, P. M. The Potential Diagram for Oxygen at pH 7. Biochem. J. 1988, 253 (1), 287-289.

(49) Aeschbacher, M.; Graf, C.; Schwarzenbach, R. P.; Sander, M. Antioxidant Properties of Humic Substances. Environ. Sci. Technol. 2012, 46 (9), 4916-4925.

(50) Wenk, J.; Canonica, S. Phenolic Antioxidants Inhibit the Triplet-Induced Transformation of Anilines and Sulfonamide Antibiotics in Aqueous Solution. Environ. Sci. Technol. 2012, 46 (10), $5455-5462$.

(51) Janssen, E. M.-L.; Erickson, P. R.; McNeill, K. Dual Roles of Dissolved Organic Matter as Sensitizer and Quencher in the Photooxidation of Tryptophan. Environ. Sci. Technol. 2014, 48 (9), $4916-4924$ 
(52) Asada, K.; Kiso, K. Initiation of Aerobic Oxidation of Sulfite by Illuminated Spinach Chloroplasts. Eur. J. Biochem. 1973, 33 (2), 253257.

(53) Fridovich, I.; Handler, P. Utilization of the Photosensitized Oxidation of Sulfite for Manometric Actinometry. Biochim. Biophys. Acta 1959, 35, 546-547.

(54) Fridovich, I.; Handler, P. Detection of Free Radicals in Illuminated Dye Solutions by the Initiation of Sulfite Oxidation. J. Biol. Chem. 1960, 235 (6), 1835-1838.

(55) Vepřke-Siška, J.; Lunák, S. Effects of Trace Metals on the Photosensitized Autoxidation of Sulphite. J. Photochem. 1978, 8 (5), 391-396.

(56) Srinivasan, V. S.; Podolski, D.; Westrick, N. J.; Neckers, D. C. Photochemical Generation of Superoxide Ion $\left(\mathrm{O}_{2}{ }^{--}\right)$by Rose Bengal and $\mathrm{Ru}(\text { bpy })_{3}{ }^{2+}$. J. Am. Chem. Soc. 1978, 100 (20), 6513-6515.

(57) Yang, S. F. Reactions of Oxidation Intermediates of Sulphite Species with Some Cellular Components of Plants. Food Chem. 1984, 15 (2), 113-124

(58) Finlayson-Pitts, B. J.; Pitts, J. N. Chapter 8 - Acid Deposition: Formation and Fates of Inorganic and Organic Acids in the Troposphere. In Chemistry of the Upper and Lower Atmosphere; Finlayson-Pitts, B. J., Pitts, J. N., Eds.; Academic Press: San Diego, 2000; pp 294-348, DOI: 10.1016/B978-012257060-5/50010-1.

(59) Alyea, H. N.; Bäckström, H. L. J. The Inhibitive Action of Alcohols on the Oxidation of Sodium Sulfite. J. Am. Chem. Soc. 1929, 51 (1), 90-109.

(60) Olson, T. M.; Hoffmann, M. R. Hydroxyalkylsulfonate Formation: Its Role as a S(IV) Reservoir in Atmospheric Water Droplets. Atmos. Environ. 1989, 23 (5), 985-997.

(61) de Azevedo, L. C.; Reis, M. M.; Motta, L. F.; Rocha, G. O.; da Silva, L. A.; de Andrade, J. B. Evaluation of the Formation and Stability of Hydroxyalkylsulfonic Acids in Wines. J. Agric. Food Chem. 2007, 55 (21), 8670-8680.

(62) Sheridan, M. K.; Elias, R. J. Reaction of Acetaldehyde with Wine Flavonoids in the Presence of Sulfur Dioxide. J. Agric. Food Chem. 2016, 64 (45), 8615-8624.

(63) Lambert, C. R.; Kochevar, I. E. Does Rose Bengal Triplet Generate Superoxide Anion? J. Am. Chem. Soc. 1996, 118 (13), 3297-3298.

(64) Treinin, A.; Hayon, E. Quenching of Triplet States by Inorganic Ions. Energy Transfer and Charge Transfer Mechanisms. J. Am. Chem. Soc. 1976, 98 (13), 3884-3891.

(65) Chawla, O. P.; Arthur, N. L.; Fessenden, R. W. Electron Spin Resonance Study of the Photolysis of Aqueous Sulfite Solutions. J. Phys. Chem. 1973, 77 (6), 772-776.

(66) Wang, X.; Gemayel, R.; Hayeck, N.; Perrier, S.; Charbonnel, N.; Xu, C.; Chen, H.; Zhu, C.; Zhang, L.; Wang, L.; Nizkorodov, S. A.; Wang, X.; Wang, Z.; Wang, T.; Mellouki, A.; Riva, M.; Chen, J.; George, C. Atmospheric Photosensitization: A New Pathway for Sulfate Formation. Environ. Sci. Technol. 2020, 54 (6), 3114-3120.

(67) García-Galán, M. J.; Díaz-Cruz, M. S.; Barceló, D. Determination of 19 Sulfonamides in Environmental Water Samples by Automated On-Line Solid-Phase Extraction-Liquid Chromatography-Tandem Mass Spectrometry (SPE-LC-MS/MS). Talanta 2010, 81 (1), 355-366.

(68) Boreen, A. L.; Arnold, W. A.; McNeill, K. Triplet-Sensitized Photodegradation of Sulfa Drugs Containing Six-Membered Heterocyclic Groups: Identification of an $\mathrm{SO}_{2}$ Extrusion Photoproduct. Environ. Sci. Technol. 2005, 39 (10), 3630-3638.

(69) Li, M.; Wang, C.; Yau, M.; Bolton, J. R.; Qiang, Z. Sulfamethazine Degradation in Water by the VUV/UV Process: Kinetics, Mechanism and Antibacterial Activity Determination Based on a Mini-Fluidic VUV/UV Photoreaction System. Water Res. 2017, 108 (Supplement C), 348-355.

(70) Shah, S.; Hao, C. Quantum Chemical Investigation on Photodegradation Mechanisms of Sulfamethoxypyridazine with Dissolved Inorganic Matter and Hydroxyl Radical. J. Environ. Sci. 2017, 57, 85-92.
(71) Ji, Y.; Shi, Y.; Wang, L.; Lu, J.; Ferronato, C.; Chovelon, J.-M. Sulfate Radical-Based Oxidation of Antibiotics Sulfamethazine, Sulfapyridine, Sulfadiazine, Sulfadimethoxine, and Sulfachloropyridazine: Formation of $\mathrm{SO}_{2}$ Extrusion Products and Effects of Natural Organic Matter. Sci. Total Environ. 2017, 593-594, 704-712.

(72) Feng, Y.; Wu, D.; Deng, Y.; Zhang, T.; Shih, K. Sulfate RadicalMediated Degradation of Sulfadiazine by $\mathrm{CuFeO}_{2}$ Rhombohedral Crystal-Catalyzed Peroxymonosulfate: Synergistic Effects and Mechanisms. Environ. Sci. Technol. 2016, 50 (6), 3119-3127.

(73) Yang, H.; Zhuang, S.; Hu, Q.; Hu, L.; Yang, L.; Au, C.; Yi, B. Competitive Reactions of Hydroxyl and Sulfate Radicals with Sulfonamides in $\mathrm{Fe}^{2+} / \mathrm{S}_{2} \mathrm{O}_{8}{ }^{2-}$ System: Reaction Kinetics, Degradation Mechanism and Acute Toxicity. Chem. Eng. J. 2018, 339, 32-41.

(74) Feng, M.; Baum, J. C.; Nesnas, N.; Lee, Y.; Huang, C.-H.; Sharma, V. K. Oxidation of Sulfonamide Antibiotics of Six-Membered Heterocyclic Moiety by Ferrate(VI): Kinetics and Mechanistic Insight into $\mathrm{SO}_{2}$ Extrusion. Environ. Sci. Technol. 2019, 53 (5), 2695-2704.

(75) Fu, W.; Li, B.; Yang, J.; Yi, H.; Chai, L.; Li, X. New Insights into the Chlorination of Sulfonamide: Smiles-Type Rearrangement, Desulfation, and Product Toxicity. Chem. Eng. J. 2018, 331, 785-793.

(76) Yang, L.; Shi, Y.; Li, J.; Fang, L.; Luan, T. Transformation of Aqueous Sulfonamides under Horseradish Peroxidase and Characterization of Sulfur Dioxide Extrusion Products from Sulfadiazine. Chemosphere 2018, 200, 164-172.

(77) Yang, J.-F.; He, M.; Wu, T.-F.; Hao, A.-P.; Zhang, S.-B.; Chen, Y.-D.; Zhou, S.-B.; Zhen, L.-Y.; Wang, R.; Yuan, Z.-L.; Deng, L. Sulfadiazine Oxidation by Permanganate: Kinetics, Mechanistic Investigation and Toxicity Evaluation. Chem. Eng. J. 2018, 349, 5665 .

(78) Givens, R. S.; Hrinczenko, B.; Liu, J. H. S.; Matuszewski, B.; Tholen-Collison, J. Photoextrusion of Sulfur Dioxide from Aryl Methyl Sulfones: Exploration of the Mechanism by Chemical Trapping, Chiral and CIDNP Probes. 27. J. Am. Chem. Soc. 1984, 106 (6), 1779-1789.

(79) Shiraki, S.; Garcia-Garibay, M. A. Carbon-Carbon Bond Formation by the Photoelimination of Small Molecules in Solution and in Crystals. In Handbook of Synthetic Photochemistry; John Wiley \& Sons, Ltd.: 2010; pp 25-66, DOI: 10.1002/9783527628193.ch2.

(80) Fujii, M.; Otani, E. Photochemical Generation and Decay Kinetics of Superoxide and Hydrogen Peroxide in the Presence of Standard Humic and Fulvic Acids. Water Res. 2017, 123, 642-654.

(81) Zhang, Y.; Del Vecchio, R.; Blough, N. V. Investigating the Mechanism of Hydrogen Peroxide Photoproduction by Humic Substances. Environ. Sci. Technol. 2012, 46 (21), 11836-11843. 